\title{
Development of NSTX Particle Control Techniques
}

H.W. Kugel, R. Maingi, M. Bell, D. Gates, K. Hill, B. LeBlanc, D. Mueller, R. Kaita, S. Paul, S. Sabbagh, C.H. Skinner, V. Soukhanovskii, B. Stratton, R. Raman

This article was submitted to $16^{\text {th }}$ International Conference on Plasma Surface Interactions, Portland, Maine, May 24-28, 2004

\section{June 2004}




\section{DISCLAIMER}

This document was prepared as an account of work sponsored by an agency of the United States Government. Neither the United States Government nor the University of California nor any of their employees, makes any warranty, express or implied, or assumes any legal liability or responsibility for the accuracy, completeness, or usefulness of any information, apparatus, product, or process disclosed, or represents that its use would not infringe privately owned rights. Reference herein to any specific commercial product, process, or service by trade name, trademark, manufacturer, or otherwise, does not necessarily constitute or imply its endorsement, recommendation, or favoring by the United States Government or the University of California. The views and opinions of authors expressed herein do not necessarily state or reflect those of the United States Government or the University of California, and shall not be used for advertising or product endorsement purposes.

This is a preprint of a paper intended for publication in a journal or proceedings. Since changes may be made before publication, this preprint is made available with the understanding that it will not be cited or reproduced without the permission of the author.

This report has been reproduced directly from the best available copy.

Available to DOE and DOE contractors from the

Office of Scientific and Technical Information

P.O. Box 62, Oak Ridge, TN 37831

Prices available from (423) 576-8401

http: / / apollo.osti.gov/bridge/

Available to the public from the National Technical Information Service

U.S. Department of Commerce 5285 Port Royal Rd., Springfield, VA 22161 http:/ / www.ntis.gov/

OR

Lawrence Livermore National Laboratory Technical Information Department's Digital Library http:/ / www.llnl.gov/tid/Library.html 


\title{
Development of NSTX particle control techniques
}

\author{
H. W. Kugel ${ }^{\text {a }}$, R. Maingi ${ }^{\text {b }}$, M. Bell ${ }^{\text {a }}$, D. Gates ${ }^{\text {a }}$, K. Hill ${ }^{\text {a }}$, B. LeBlanc ${ }^{\text {a }}$, \\ D Mueller ${ }^{\text {a }}$, R. Kaita ${ }^{\text {a }}$, S. Paul a , S. Sabbagh ${ }^{\text {c }}$, C. H. Skinner ${ }^{\text {a }}$, \\ V. Soukhanovskii ${ }^{\mathrm{d}}$, B. Stratton ${ }^{\mathrm{a}}$, R. Raman ${ }^{\mathrm{e}}$ \\ ${ }^{a}$ Princeton Plasma Physics Laboratory, Princeton, NJ 08543, USA. \\ ${ }^{b}$ Oak Ridge National Laboratory, Oak Ridge, TN 37831, USA \\ ${ }^{e}$ Columbia University, New York, NY, 10027, USA \\ 'Lawrence Livermore National Laboratory, Livermore, CA 94551, USA \\ ${ }^{e}$ University of Washington, Seattle, WA,98195, USA
}

\begin{abstract}
NSTX High Harmonic Fast Wave (HHFW) current drive discharges will require density control for acceptable efficiency. We have compared boronization on hot and cold surfaces, varying helium glow discharge conditioning (HeGDC) durations, and brief morning boronization with between discharge boronization for improving density control. Access to Ohmic H-modes was enabled by boronizationon on hot surfaces, however, the duration of the effectiveness of hot and cold boronization was comparable. A 15 min HeGDC between discharges was needed for reproducible L-H transitions. Brief morning boronization followed by a comparable duration of applied HeGDC restored and enhanced good conditions. Additional short boronizations between discharges did not improve plasma performance (reduced recycling, reduced impurity luminosities, earlier L-H transitions, longer plasma current flattops, higher stored energies) if conditions were already good. Between discharge boronization requires increases in the duty cycle due to the need for additional HeGDC to remove codeposited $\mathrm{D}_{2}$.
\end{abstract}

PSI16 Subject Categories: Wall conditioning; Impurity control; Glow discharge cleaning; discharge cleaning.

JNM Keywords: I0100 Impurities; S1300 Surface effects; F0400 First wall interactions; P0500 Plasma-materials interaction.

PAC Numbers: 52.25.Vy; 52.40.-w; 52.40.Hf; 52.55.Fa.

* Corresponding author address: PPPL, P.O.Box 451, Princeton NJ 08543.

* Corresponding author email: hkugel@pppl.gov.

* Presenting author: H.W. Kugel, email: hkugel@pppl.gov. 


\section{Introduction}

The investigation of non-inductive current drive with the goal of eliminating the central solenoid from future machines is a major focus of international Spherical Torus research and the National Spherical Torus Experiment (NSTX) program [1]. Elements of the NSTX current drive research program include High Harmonic Fast Wave (HHFW) current drive ( 100kA achieved) and Coaxial Helicity Injection (CHI) (400 kA achieved). Integrated scenario modeling of NSTX HHFW current drive discharges [2] shows that an average plasma density less than $n_{e} \sim 3 \times 10^{19} \mathrm{~m}^{-3}$ is optimal for acceptable HHFW current drive efficiency. However, during long-pulse NBI-heated H-modes, the density rises continuously, reaching up to $\mathrm{n}_{\mathrm{e}} \sim 7 \times 10^{19} \mathrm{~m}^{-3}$ in $0.3 \mathrm{~s}$. Analysis of the time dependence of these density rises [3] has found $\zeta^{*} \sim 0.5 \mathrm{~s}$ or $\sim 10 \mathrm{x} \square_{\mathrm{E}}$. It has become evident that the existing NSTX particle control techniques $[4,5]$ of gas puffing, high temperature PFC bakeout, boronization on room temperature substrates, and brief HeGDC wall conditioning between discharges need augmenting to provide plasma density control for longer pulse operation.

We report on a comparison of boronization on hot and cold substrates, brief morning boronization, between discharge boronization, extended HeGDC between discharges, and $\mathrm{He}$ discharge conditioning to reduce and control spontaneous density rises, and in particular control Ц* for improved HHFW current drive efficiency, as well as, for transport studies, and power and particle handling research.

\section{Comparison of boronization on hot and cold surfaces}

The NTSX plasma facing surface is about $41 \mathrm{~m}^{2}$, consisting of graphite tiles on power handling surfaces (75.6\%), and the 304-SS midplane vessel wall (24.4\%). During bakeout following a vent, the graphite is baked to $300-350^{\circ} \mathrm{C}$ and the vessel walls to $150^{\circ} \mathrm{C}$. 25 boronizations have been performed on the room temperature plasma facing surfaces using about $10 \mathrm{~g}$ of deuterated trimethyl boron $\left(\mathrm{B}\left(\mathrm{CD}_{3}\right)_{3}\right)$ injected into a HeGDC [6]. Based on machine performance and spectroscopic signals indicative of relatively higher impurity luminosities, these boronizations have been performed in NSTX every 200-400 discharges or about every 2-3 weeks. Although such room temperature boronization has been effective in enabling high performance in NSTX to date $[4,5]$, a test of boronization on high temperature substrates was made. The goal of testing the effectiveness of hot boronization on graphite 
surfaces $\left(300-350^{\circ} \mathrm{C}\right)$ and the vessel wall $\left(150^{\circ} \mathrm{C}\right)$ was to determine if changes in codeposition, deposited film microstructure, and uniformity could reduce impurity traps and recycling. A hot boronization was performed after pump-down, following a short venting of the vessel. The hot and cold (room temperature) boronizations were compared using D lower single null (LSN), $600 \mathrm{kA}$ plasma current $\left(\mathrm{I}_{\mathrm{p}}\right)$, Ohmic, and LSN, Ip $800 \mathrm{kA}$, NBI fiducial discharges.

Following hot boronization, a significant improvement in the performance of the initial Ohmic and NBI fiducial discharges was observed relative to those following cold boronization. The Ohmic fiducial discharges exhibited the most favorable Ohmic performance to date. The previously elusive Ohmic H-mode was achieved after the 2nd discharge, and maintained in many discharges thereafter. This relatively facile transitioning to the Ohmic H-mode may be related to the lower $\mathrm{D}_{\square}$ luminosity observed after hot boronization, which may in turn be due to less retention of codeposited $D_{2}$ during boronization on hot surfaces, and possible reduced porosity and trapping sites in depositions on higher temperature surfaces. Laboratory work has indicated that boron films grown at high temperatures exhibit characteristics that imply a different microstructure $[7,8]$. The D LSN NBI fiducial discharges exhibited the most promising first-day-NBI operation to date following a vent. However, although the first NBI fiducial discharges transitioned easily to $\mathrm{H}$-modes, these discharges exhibited a $\mathrm{D}_{\square}$ luminosity comparable to NBI discharges following cold boronization. This may have been due to the $\mathrm{D}_{2}$ wall loading resulting from the 56 Ohmic discharges that preceded the D LSN NBI fiducial discharges. However, while the initial performance of NBI fiducials following hot boronization was significantly improved relative to cold boronization, as the fluence to the wall increased with succeeding NBI discharges, the operating conditions following hot boronization deteriorated (increased recycling, increased impurity luminosities, later L-H transitions, shorter $\mathrm{I}_{\mathrm{p}}$ flattops, lower stored energies), and became indistinguishable from those following cold boronization, In addition, the durations of the improved operating conditions following hot and cold boronization were found to be comparable (Fig. 1). These results may indicate that as the fluence to the wall increases, erosion and similar changes to the deposition microstructure eventually dominated over the initial deposition conditions. 


\section{Comparison of between discharge HeGDC and helium discharge conditioning}

The duration of between discharge HeGDC was varied to optimize conditions for density control, boundary physics characterization experiments, and sensitive studies of early $\mathrm{H}$-mode access as a method for limiting rapid penetration of the current density during ramp up to achieve access to $q_{\min }>>1$ at the end of the current ramp up. It was found that a 15 minute HeGDC between discharges was needed for reproducible timing of the L-H transition. Shorter HeGDC applications were found to delay the L-H transition, and may eventually result in a higher L-H power threshold by mid or latter part of run day. Fig. 2 shows the time of the L-H transition moves earlier in the discharge as the duration of the applied GDC is increased.

Fig. 3 compares the density rise for D, LSN, NBI discharges after the application 15 minutes of HeGDC between discharges and a technique with a 5 minute HeGDC preceding and following by a double null diverted (DND), He, $\mathrm{I}_{\mathrm{p}} 500 \mathrm{kA}$, Ohmic conditioning discharge. Preceding D discharges with He conditioning discharges provided better density control than only preceding the D discharges with HeGDC. This provides a prescription for slowing the rise in density during ramp up and improving density control.

\section{Comparison of short morning boronization and between discharge boronization}

The standard NSTX boronizations have applied $\sim 10 \mathrm{~g}$ in $\sim 140$ minutes, at a rate of one per 2 to 3 weeks (after 300-400 discharges) [6]. Experiments were performed to investigate ways that might stabilize conditions between boronizations, and when conditions are good to determine if they could be improved. These experiments focused on the following questions: "Is a short morning boronization (prior to daily operation) sufficient? If morning boronization is good, is between discharge boronization even better? Does more frequent, shorter boronization improve reproducibility?".

Morning and between discharge boronization were tested about midway between 2 standard boronizations. In order to determine the optimal balance between the duration of boronization, the required HeGDC for desorbing the codeposited deuterium, and the subsequent fiducial performance, 5 short boronizations were performed, ranging in duration from 1 minute to 17 minutes followed by HeGDC applications ranging from 5 to 30 mins. 
Fig. 4 shows the relative luminosities following a 17 min morning boronization followed by a 17 min HeGDC and a 15 min boronization followed by a 30 min HeGDC using high performance LSN NBI fiducials. It was found that the luminosity ratios for Da/BII measured at $0.250 \mathrm{sec}$ exhibited the largest fraction change. The BII/CIII luminosity ratio was relatively constant. This may be due to the signals measured both then fresh and residual passivated products (B and C) from previous standard boronizations, and hence, sampled approximately the same deposition stoichiometry. Fig. 5 shows the experimental sequence used for comparing the effect of various short boronizations, different durations of HeGDC, and Helium conditioning discharges using DND NB fiducials. Preceding the D discharges with He discharge conditioning was more effective than HeGDC alone in restoring good conditions. The resultant conditions were later used to produce the LSN discharges with the highest stored energies for a 2 NBI discharges to date $\left(\sim 300 \mathrm{~kJ}, \square_{\mathrm{E}} \sim 45-50 \mathrm{msec}\right)$.

\section{Conclusions}

It was found that boronization on hot surfaces yields a significant improvement in initial operating conditions (lower recycling, lower impurity luminosities, earlier L-H transitions, longer $I_{p}$ flattops, higher stored energies) relative to boronization on cold surfaces, but that the duration of the improved operating conditions following hot and cold boronization was comparable as fluence to the wall increased with succeeding discharges. A 15 min HeGDC between discharges was needed for reproducible L-H transition timing. Brief morning boronization followed by a comparable duration of applied HeGDC restored and enhanced good operating conditions. Additional short boronization between discharges with relatively good operating conditions produced no improvement. Between discharge boronization increases duty cycle due to the need to apply HeGDC for a sufficient duration to remove codeposited $D_{2}$. Remaining questions involve using between discharge sample analysis to measure changes in microstructure as fluence increases, determining the most sensitive fiducial discharges and the optimal figures of merit for determining the frequency of applying morning boronization. In addition, more work is needed to determine the optimal balance between the frequency of applying boronization, the amount of boronization (duration), and the duration of the succeeding HeGDC for reproducible operating conditions and accessing high performance regimes. 


\section{Acknowledgment}

This work is supported by U.S. Department of Energy Contracts, DE-AC0276CH03073, DE-AC05-00OR22725, DE-FG02-99ER54523 and DE-FG03-99ER54361, W7405-ENG-36, We wish to acknowledge the technical contributions of W. Blanchard, J. Winston, T. Czeizinger J. Desandro, J. Gething, J. Kukon and the NSTX Engineering and National Research Teams.

This work was performed under the auspices of the U.S. Department of Energy by the University of California, Lawrence Livermore National Laboratory under Contract No. W-7405-Eng-48. 


\section{References}

[1] E. Synakowski, et al., Nuc. Fusion, 43 (2003) 1653.

[2] C. Kessel, NSTX 5-Year Plan Review, June 2003, Princeton, NJ.

[3] R. Maingi, et al., Plasma Physics of Controlled Fusion, 45 (2003) 657.

[4] C. H. Skinner, et al., Nucl. Fusion 42 (2002) 329.

[5] H.W. Kugel, et al., J. Nucl. Mater. 313-316 (2003) 187.

[6] W. Blanchard, et al., Proceedings of the IEEE/NPSS Symposium on Fusion Engineering in Atlantic City, NJ, January 21-25, 2002.

[7] S. Veprek, et al., J. Nucl. Mater. 162-164 (1989) 724.

[8] J. Winter in "Physical Processes of the Interaction of Fusion Plasmas with Solids", Academic Press, 1996, p 217. 


\section{Figure Captions}

Fig. 1 Core luminosity ratios for LSN NB fiducial discharges after hot (B-23) and cold (B-24, B-25) boronization.

Fig. 2 The change in time ( $\mathrm{sec}$ ) of the L-H transition from the L-H transition in the preceding discharge. The L-H transition moves earlier in the discharge as the duration of the applied HeGDC is increased.

Fig. 3 Comparison of the line integrated density $\left(\mathrm{cm}^{-2}\right)$ rises for D LSN, fiducial discharges preceded and succeeded by different durations of HeGDC and a He conditioning discharge. Both discharges transitioned to $\mathrm{H}$-mode, but the discharge preceded by the He conditioning discharge had a lower density rise which caused a locked mode (rare in H-modes).

Fig. 4 Relative change in luminosity ratios following short boronizations followed by a comparable duration of HeGDC.

Fig. 5 Conditioning sequence for comparing the effect of various short boronizations, different durations of HeGDC and Helium conditioning discharges using DND NB fiducials. 


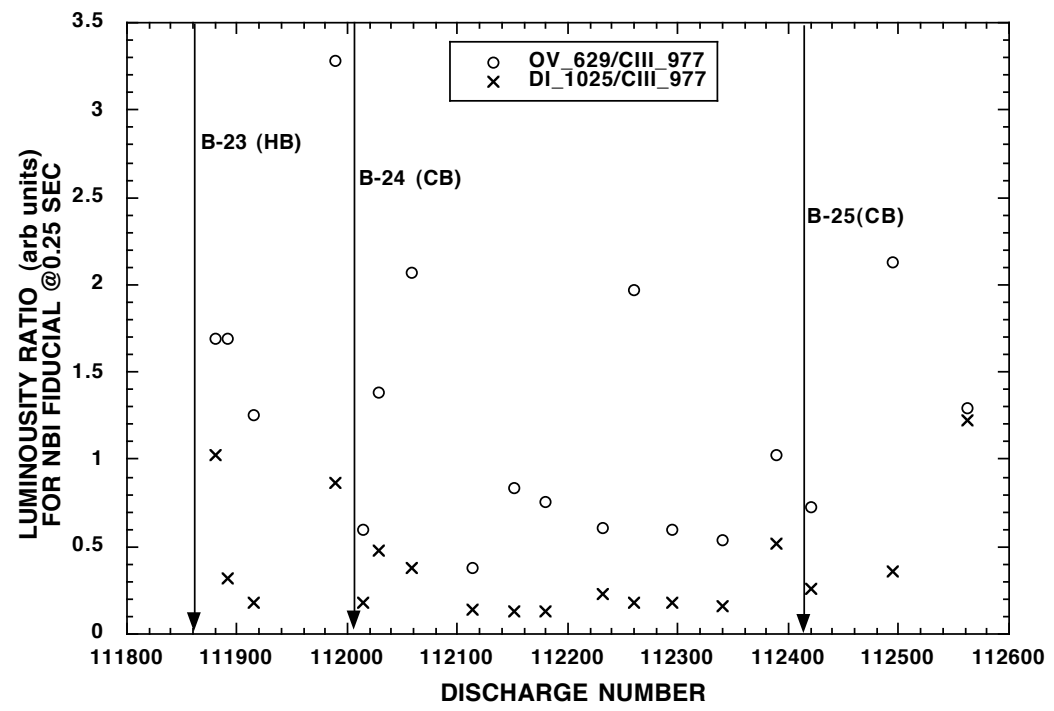

Fig. 1 Core luminosity ratios for LSN NB fiducial discharges after hot (B-23) and cold (B-24, B-25) boronization. 


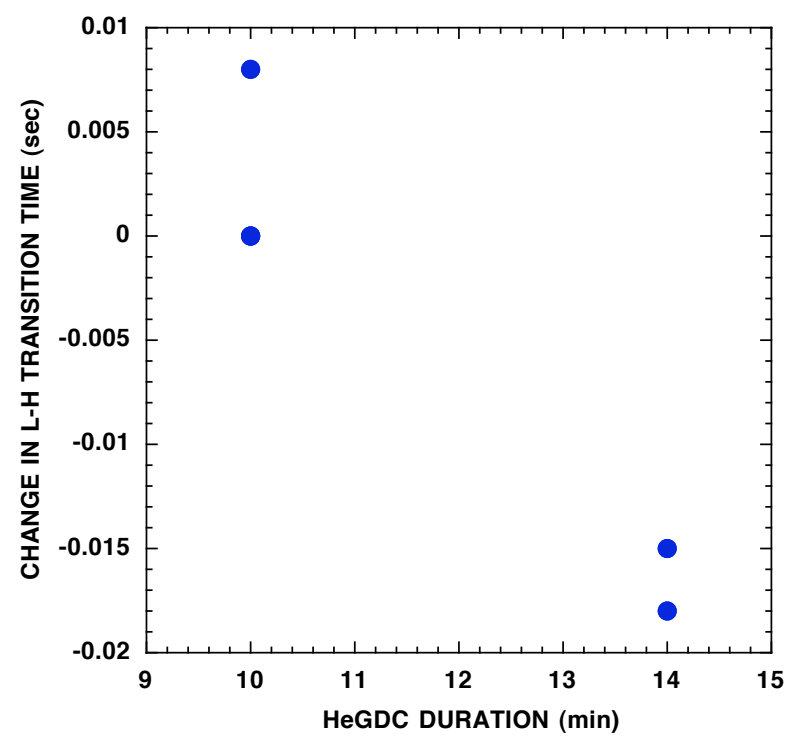

Fig. 2 The change in time (sec) of the L-H transition from the L-H transition in the preceding discharge. The L-H transition moves earlier in the discharge as the duration of the applied HeGDC is increased. 


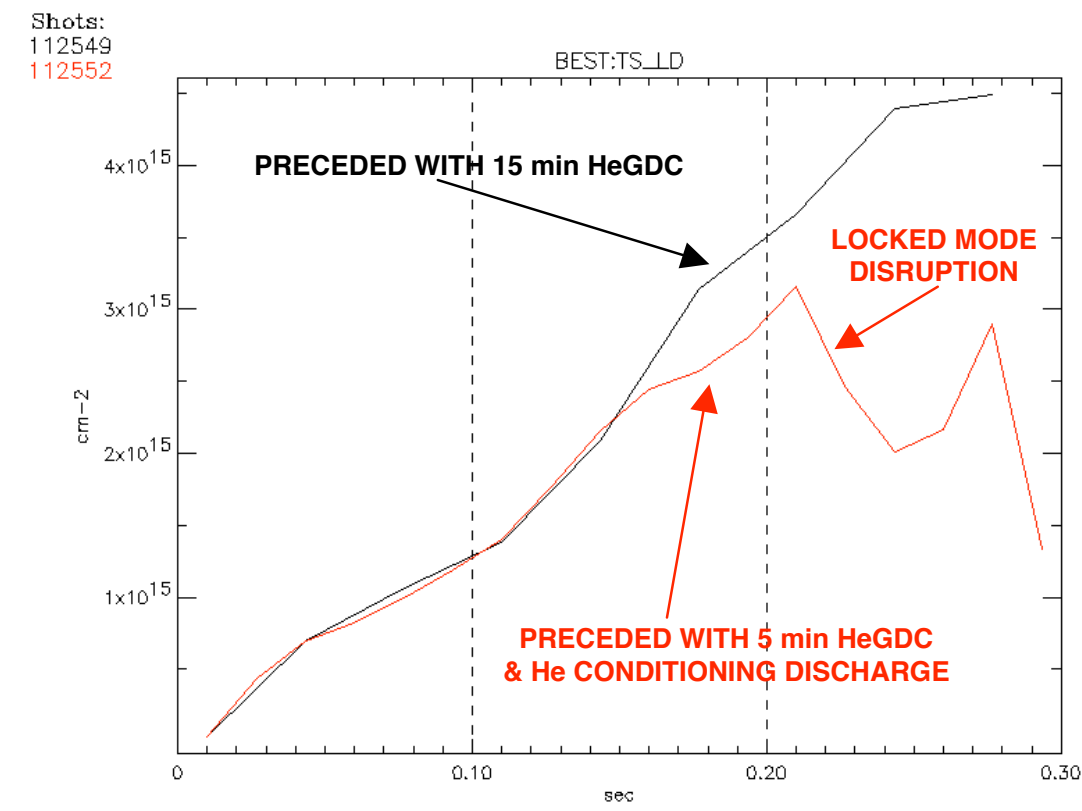

Fig. 3 Comparison of the line integrated density $\left(\mathrm{cm}^{-2}\right)$ rises for D LSN, fiducial discharges preceded and succeeded by different durations of HeGDC and a He conditioning discharge. Both discharges transitioned to H-mode, but the discharge preceded by the He conditioning discharge had a lower density rise which caused a locked mode (rare in H-modes). 
P2-32

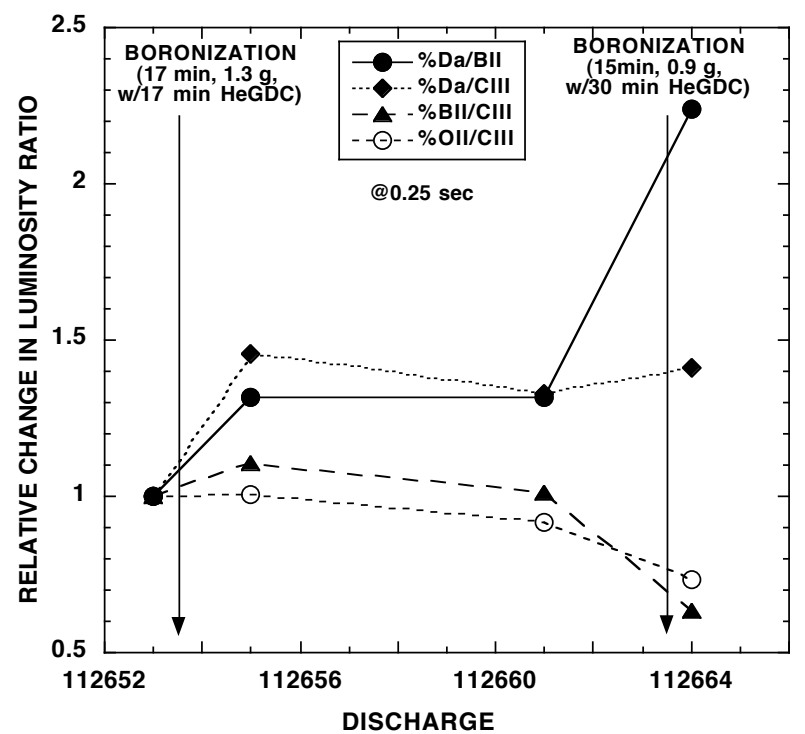

Fig. 4 Relative change in luminosity ratios following short boronizations followed by a comparable duration of HeGDC. 


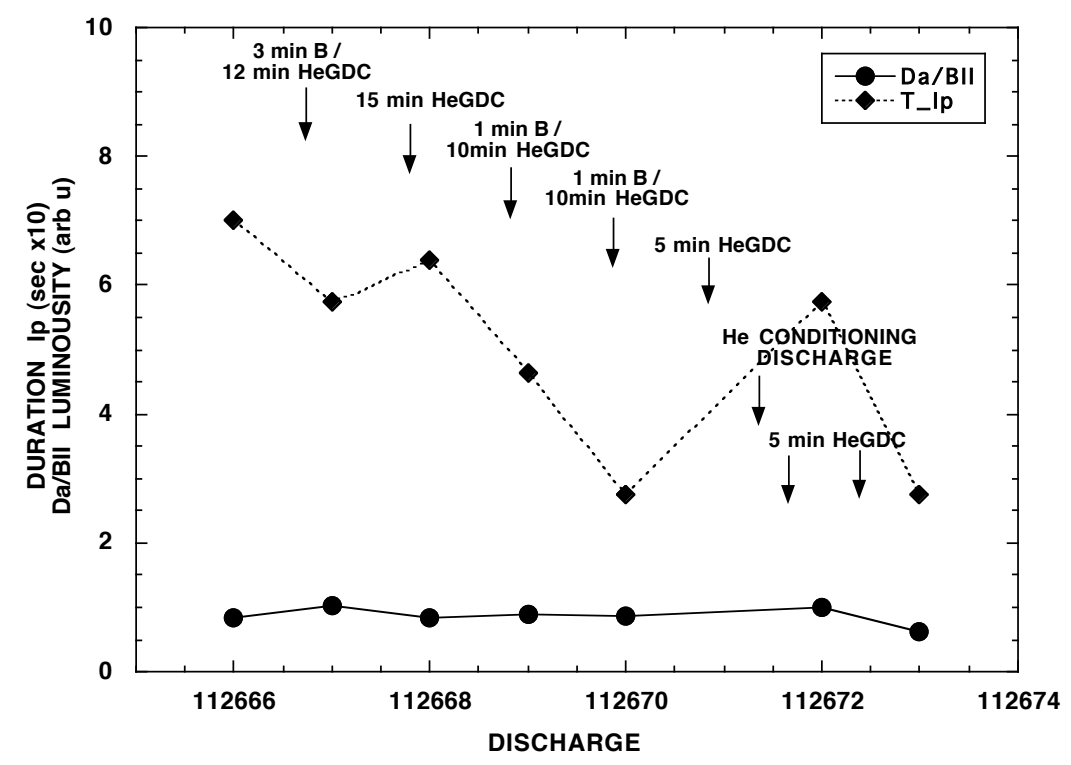

Fig. 5 Conditioning sequence for comparing the effect of various short boronizations, different durations of HeGDC and Helium conditioning discharges using DND NB fiducials. 
Univverilty of California

Lawrence Livermere National Laboratery

Technical Information Department

Livermore, CA 94551

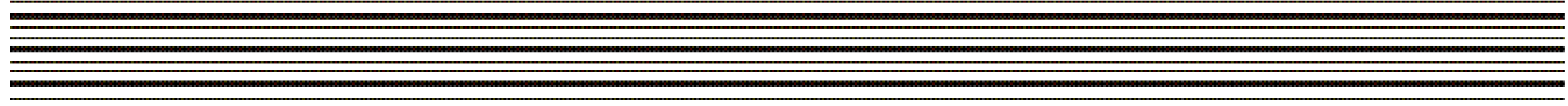

